\title{
The Influence Of Confining Pressure On The Flow Field Structure Of Submerged Water Jet Xiaofeng Yang
}

\author{
Shenzhen Institute of Wuhan University, Shenzhen, China
}

Key words: water jet, submerged jet, confining pressure, flow field structure

Abstract: the study of the change of water jet in submerged condition is an important foundation of the exploitation of offshore hydrocarbons depending on water jet technology. The characteristics of the flow field structure in different confining pressure conditions are analyzed theoretically and numerically. By comparing the flow field of water jet gained through numerical simulation under different confining pressures, the maximum velocity of the jet is found to decrease with the increase of confining pressure. The results also indicated that the change of confining pressure has hardly any effect on the size and configuration of the core section of a submerged jet. The conclusion has a positive significance for improving the efficiency of offshore oil-gas exploitation.

\section{Introduction}

The exploitation and exploration of offshore oil-gas resources has become a necessary means to ensure the energy supply in our country. However, factors such as the constant change of water pressure, the influence of high pressure and a different working environment under water, are making the application of traditional drilling technology more troublesome. Therefore, the research on the new technology of underwater drilling is the main task nowadays ${ }^{[1-2]}$.

The occurrence of the water jet technology has provided us a broader prospect for the marine hydrocarbon exploration. Extensive research has been carried out in the field of submerged water jet ${ }^{[5]}$, submerged cavitation jet cutting, rock breaking and cleaning ${ }^{[3-4]}$. The erosion of water jet is studied under laboratory conditions at the same time. Despite the optimistic prospect, water jet for offshore oil-gas exploitation faces much of challenges. Compared with water jet for general uses, the water jet assisting offshore oil and gas drilling, which is carried out under the submerged condition without a clear impacting mechanism of specific effects of different confining pressures on the structure of the jet flow field. Aiming at the problems existing in the practical engineering application of offshore oil and gas exploitation, a study of the influence of confining pressure on the flow field structure of submerged water jet is made, which is of positive significance to both researches on theory and technologies of offshore oil-gas exploitation with water jet and increasing efficiency itself. 


\section{nozzle flow field structure under different confining pressures}

The conical nozzle is a nozzle type widely used on cutting and breaking. With a higher discharge coefficient compared to cone convergent nozzle, its fluid density can meet the production requirements and simplify the machining compared with streamline nozzles. Therefore, the study select conical cylindrical convergent nozzle as nozzle structure ${ }^{[6]}$. The diameter of orifice has a great influence on the speed of the jet and the diameter of the punching hole ${ }^{[7]}$. The rate of flow increases while the outlet velocity decreases in case of the diameter and the pump pressure increases accordingly. Nozzle outlet diameter $d_{0}$ can be determined by the following formula ${ }^{[8]}$ :

$$
d_{0}=0.69 \frac{q^{0.5}}{u^{0.5} p^{0.25}}
$$

Where $\mathrm{q}$ is the volume flow of the jet, $\mathrm{u}$ is 0.95 , a coefficient describing the flow coefficient of the nozzle, and the $\mathrm{P}$ is the pressure.

\section{Simulation analysis of the flow field of the ordinary nozzle under no confining pressure condition}

During industrial applications and field tests, the driving force of the fluid is provided by a pump, for which the inlet pressure is set as pumping pressure. Given that we are studying free jet in this experiment, the pressure of the outlet is set at $101325 \mathrm{~Pa}$, which is the atmospheric pressure at room temperature. The description method of turbulence at the entry and exit is the default k-e method, using the SIMPLE pressure correction algorithm. Two order upwind difference is adopted to improve the accuracy. The numerical simulation experiment is carried out to optimize the structure parameters of the nozzle, so that we can pick up the best structural parameters of the bit with the rock breaking effect. Small nozzle size leads to a low abrasive concentration. It can be regarded as liquid-solid two-phase transverse jet, so the paper choose the Eulerian two-phase flow model to describe it, water based phase, solid phase the second phase, and select an entrance to initialize the model, and then iterative calculation ${ }^{[9]}$.

The parameter of nozzle model is listed as follows: nozzle exit diameter is $2 \mathrm{~mm}$, inlet diameter is $6 \mathrm{~mm}$, and convergence angle is 13 degrees were set boundary conditions of the inlet pressure of $10 \mathrm{MPa}, 20 \mathrm{MPa}$ and $30 \mathrm{MPa}$; scheme results as follows: 


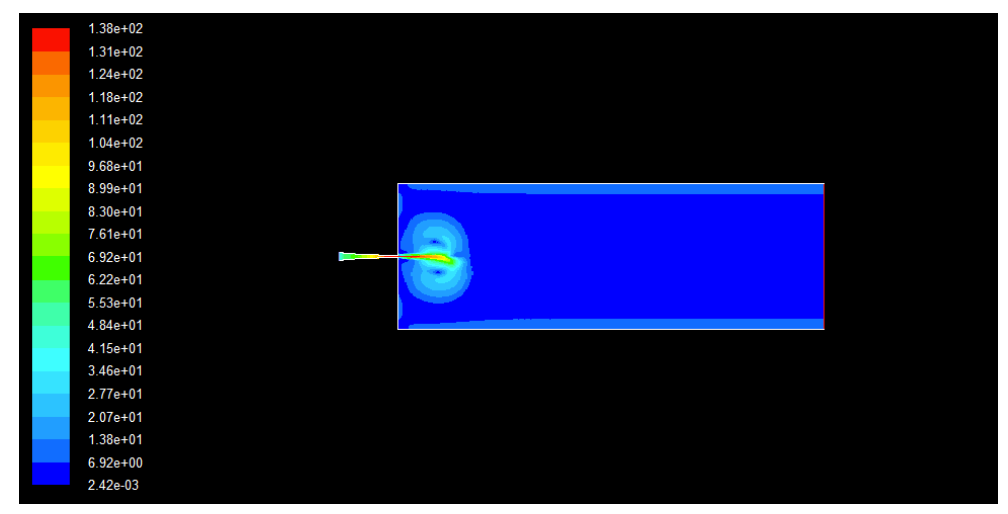

a. Inlet pressure $10 \mathrm{MPa}$

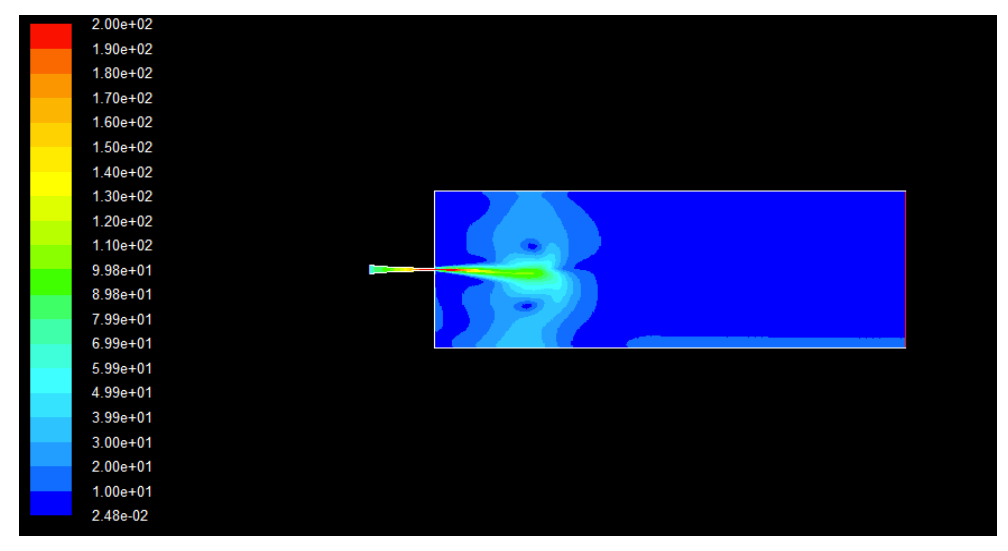

b. Inlet pressure $20 \mathrm{MPa}$

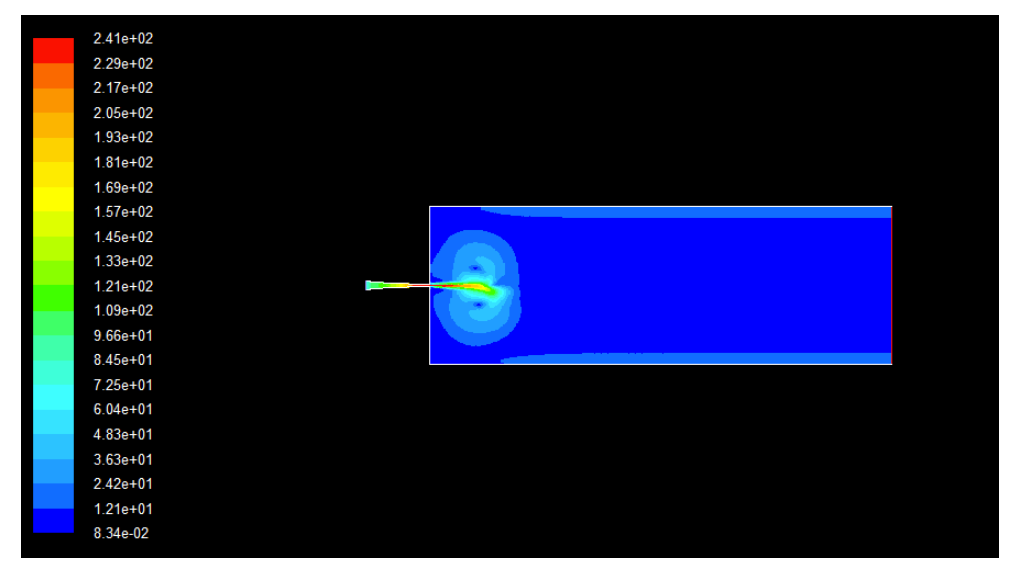

c. Inlet pressure $30 \mathrm{MPa}$

Fig. 1 Flow field structure of different inlet pressure under no confining pressure

It is obvious that the inlet pressure of different settings for the jet flow field has a measurable effect, of which the pressure of 20MPa shows a longest distance of the jet flow field and red range inferring a high speed. Though a small gap on flow velocity between the performance of 10MPa and $30 \mathrm{MPa}$, there is somehow difference when it comes to the high speed range. It is seen that the impact of the inlet pressure on the jet is not linear, that is, the point that a larger inlet pressure lead to a greater the jet exit velocity is wrong. Instead the influence of $20 \mathrm{MPa}$ pressure on the jet flow field is greater than that of $30 \mathrm{MPa}$.

Analysis of the external flow field of an ordinary nozzle under confining pressure

After sizing the grids we the flow field simulation of the jet flow field is carried out under confining 
pressure. The water under the confining pressure is given by the hydraulic calculation formula.

$$
\mathrm{P}=\mathrm{pgh}
$$

Where $\mathrm{P}$ is confining pressure, $\mathrm{p}$ is water density, $\mathrm{h}$ is water depth.

The initial boundary conditions of the simulation are $30 \mathrm{MPa}$ the inlet pressure, $4 \mathrm{MPa}, 6 \mathrm{MPa}, 8 \mathrm{MPa}$ and $2 \mathrm{MPa}$ the confining pressure. The flow field chart is as follows:

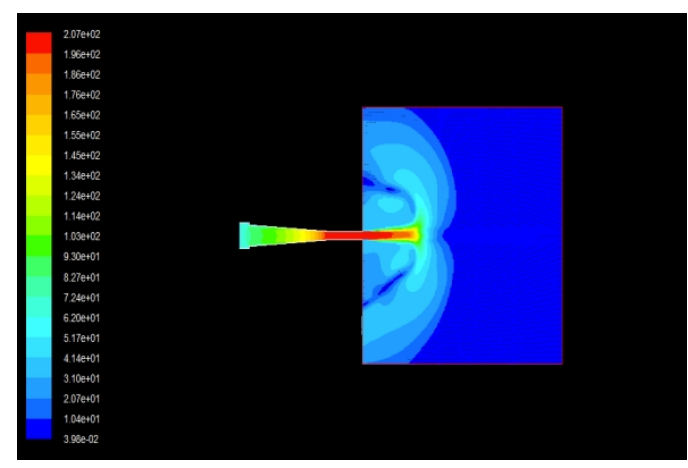

a

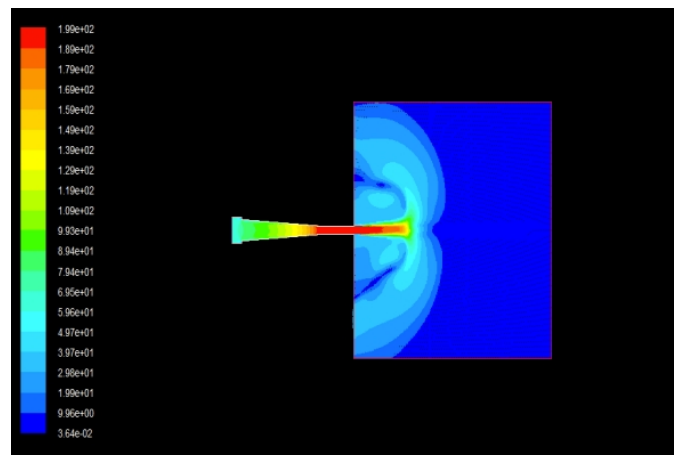

$\mathrm{C}$

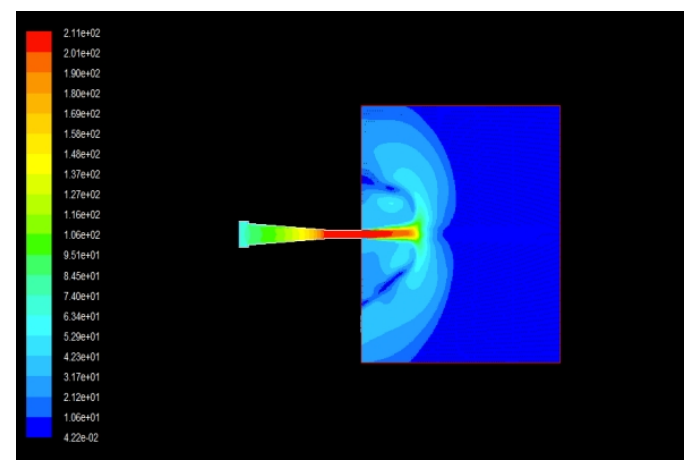

b

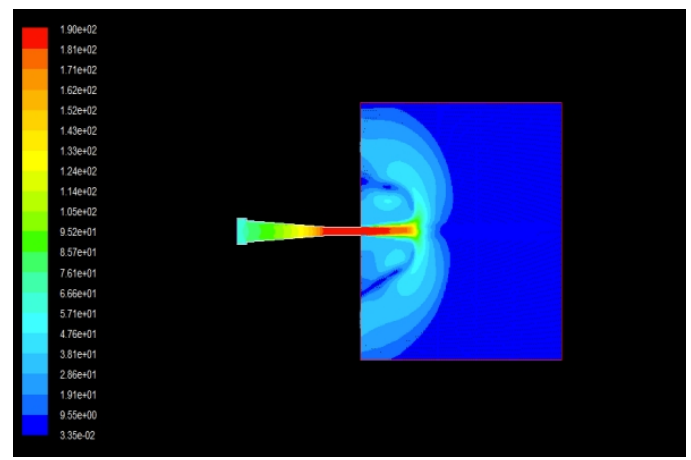

d

Fig. 2 The flow field structure of different confining pressures (a. 2MPa.b. 4MPa.c. 6MPa.d. $8 \mathrm{MPa}$.)

From the results above, it is obvious that the confining pressure of the water jet has evident effects on the velocity of the jet, that is, a higher confining pressure results in a slowing down of the jet. This conforms to the practical application of subsea engineering that higher depth of drilling requires a higher pump pressure. Besides, the comparison of the eight images shows a distinct low velocity area, which is approaching horizontal area when confining pressure increases. The area is believed to be a vortex formed at the beginning of the jet for its shape. The length of the core section is not significantly affected by the confining pressure though.

\section{conclusions}

Water jet is one of the emerging technologies in the field of offshore oil-gas exploitation. The characteristics of the flow field structure in different confining pressure conditions are analyzed by theory and numerical simulation method. By comparing the numerical simulation of water jet flow field under different confining pressures, the maximum velocity of the jet flow is decreased, but the variation of confining pressure has no obvious effect on the size and morphology of the core section. The research conclusion is positive for the development of water jet assisted marine oil and gas resources development theory and technology, and to improve the development efficiency of 
marine oil and gas resources.

\section{References}

[1] Yuanlin Ning, Shougen Hu.2002.Advances in abrasive water jet. lubricating and sealing, (01) :

$79 \sim 83$

[2] Wenying Xiang, Xiaohong Li, Yiyu Lu.2009. Experimental research on erosion of rock by submerged abrasive water jet. Journal of China University of Mining \& Technology(Social Science) $(02): 240 \sim 243$

[3] Gensheng Li, Zhongwei Huang, Shouzeng Tian.2011. Hydraulic jet fracturing theory and application. SciencePress, Beijing.

[4] Xiaojian Liu.2006. Research of abrasive slurry jet technology and mechanism. Shanghai University

[5] A. F. Conn, V.E Johnson. 1980. The fluid dynamics of submerged cavitating jet cutting, Proc. 5th Intern. Symp. on JDT

[6] Wenhui Zhou.2008. Research of high pressure water jet nozzle internal and external flow field numerical simulation. Lanzhou: Lanzhou University of Technology.

[7] Labus T J. 1995. Fluid Jet Technology Fundamentals \& Applications. USA: American Water jet Technology Association

[8] Xingduo Liu. 2014. Numerical simulation research the characteristic of pulsed nozzle jet. Sichuan: Southwest Petroleum University

[9] Zhenglong Zou.1996. The mechanism of abrasive water jet cutting coal and rock. Xuzhou: China University of Mining \& Technology 